\title{
Investigation of Kodak extended dose range (EDR) film for megavoltage photon beam dosimetry
}

\author{
Indrin J Chetty and Paule M Charland \\ Department of Radiation Oncology, The University of Michigan, Ann Arbor, MI 48109-0010, \\ USA \\ E-mail: indrin@med.umich.edu
}

Received 17 April 2002, in final form 2 September 2002

Published 3 October 2002

Online at stacks.iop.org/PMB/47/3629

\begin{abstract}
We have investigated the dependence of the measured optical density on the incident beam energy, field size and depth for a new type of film, Kodak extended dose range (Kodak EDR). Film measurements have been conducted over a range of field sizes $\left(3 \times 3 \mathrm{~cm}^{2}\right.$ to $\left.25 \times 25 \mathrm{~cm}^{2}\right)$ and depths $\left(d_{\max }\right.$ to $\left.15 \mathrm{~cm}\right)$, for $6 \mathrm{MV}$ and $15 \mathrm{MV}$ photons within a solid water phantom, and the variation in sensitometric response (net optical density versus dose) has been reported. Kodak EDR film is found to have a linear response with dose, from 0 to $350 \mathrm{cGy}$, which is much higher than that typically seen for Kodak XV film (0-50 cGy). The variation in sensitometric response for Kodak EDR film as a function of field size and depth is observed to be similar to that of Kodak $\mathrm{XV}$ film; the optical density varied in the order of $2-3 \%$ for field sizes of $3 \times 3 \mathrm{~cm}^{2}$ and $10 \times 10 \mathrm{~cm}^{2}$ at depths of $d_{\max }, 5 \mathrm{~cm}$ and $15 \mathrm{~cm}$ in the phantom. Measurements for a $25 \times 25 \mathrm{~cm}^{2}$ field size showed consistently higher optical densities at depths of $d_{\max }, 5 \mathrm{~cm}$ and $15 \mathrm{~cm}$, relative to a $10 \times$ $10 \mathrm{~cm}^{2}$ field size at $5 \mathrm{~cm}$ depth, with 4-5\% differences noted at a depth of $15 \mathrm{~cm}$. Fractional depth dose and profiles conducted with Kodak EDR film showed good agreement $(2 \% / 2 \mathrm{~mm})$ with ion chamber measurements for all field sizes except for the $25 \times 25 \mathrm{~cm}^{2}$ at depths greater than $15 \mathrm{~cm}$, where differences in the order of 3-5\% were observed. In addition, Kodak EDR film measurements were found to be consistent with those of Kodak XV film for all fractional depth doses and profiles. The results of this study indicate that Kodak EDR film may be a useful tool for relative dosimetry at higher dose ranges.
\end{abstract}

\section{Introduction}

The use of film as a method for relative dosimetry verification for photon and electron beams is a well-established standard in the field of radiation therapy (Williamson et al 1981, 
Stern et al 1992, van Bree et al 1994, van Battum and Heijmen 1995, Mayer et al 1997, Robar and Clark 1999). Advantages of film over other conventionally used measurement devices, such as ion chambers, include a higher spatial resolution, a lower cost and the ability to measure dose within a 2D plane in a single exposure. Despite these attractive features, however, the use of film as a dosimeter comes with many challenges. Studies since the early 1980s have shown that the response of film (optical density versus dose) is sensitive to many factors, such as the photon beam energy, the film orientation relative to the beam direction, air pockets within the film envelope, processing conditions and readout method, as well as intra- and inter-film variation in crystal sizes and orientation. Several investigators have reported on differences in film response when the film is positioned parallel versus perpendicular to the radiation beam (Williamson et al 1981, Cheng and Das 1996, Burch et al 1997, Robar and Clark 1999, Suchowerska et al 1999, 2001, Danciu et al 2001). Research has also focused on the influence of scatter on the film sensitometric response, caused by changing the field size and depth of the measurement (Williamson et al 1981, Evans and Schreiner 1992, Hale et al 1994, van Bree et al 1994, van Battum and Heijmen 1995, Cheng and Das 1996, Burch et al 1997, Cadman 1998, Robar and Clark 1999, Suchowerska et al 1999, 2001, Sykes et al 1999, Danciu et al 2001). The variation in results among these various works is remarkable.

Although most work on the dosimetric properties of film has so far been conducted using Kodak Readypack XV film, authors have investigated other types of film, such as Kodak RPM-2 (type M) (Williamson et al 1981), Agfa-Gevaert Structurix D2 (Danciu et al 2001), radiochromic film (Suchowerska et al 2001, Muench et al 1991, McLaughlin et al 1995) and CEA TVS film (Cheng and Das 1996, Cadman 1998). In their paper on dosimetry using CEA TVS films, Cheng and Das (1996) present electron micrographs of the crystalline structure of the CEA TVS films and Kodak XV films, showing that the silver halide crystals in the CEA TVS film are generally smaller and more uniform in size than those in Kodak XV film; the characteristic curve of the CEA film is as a result more linear than that of Kodak XV film (Cheng and Das 1996). Cheng and Das (1996) and Cadman (1998) have also shown substantially better agreement with ion chamber measurements using CEA TVS film versus that using Kodak XV film for measuring depth doses in the parallel orientation. Recently, Kodak has released a new type of film, Kodak extended dose range (Kodak EDR) film for dosimetry purposes. Kodak EDR film has the potential for being used in quality assurance for stereotactic radiosurgery as well as dose escalation in the context of intensity-modulated radiotherapy (IMRT), where delivered doses are typically much higher than those encountered in the conventional radiotherapy. Therefore, a dosimetric investigation of this new film is necessary. In this paper, we present an investigation of Kodak EDR film using $6 \mathrm{MV}$ and $15 \mathrm{MV}$ x-ray beams, namely: (a) the dependence of Kodak EDR film sensitometric response on the beam energy, field size and depth, and (b) a comparison of the accuracy of Kodak EDR film versus Kodak XV film and an ion chamber for relative depth dose and profile measurements across a range of field sizes and depths in the phantom.

\section{Materials and methods}

Measurements for Kodak EDR film were conducted together with those for Kodak XOmat V (XV) film for comparison purposes; Kodak XV film is used routinely for dosimetry and has, over the years, been extensively characterized for this purpose. Additionally, depth dose and profile film measurements over a variety of field sizes and depths have been conducted 
to determine the accuracy of Kodak EDR film versus that of Kodak XV film and the ion chamber measurements for relative dosimetry purposes. All experiments were performed with $6 \mathrm{MV}$ and $15 \mathrm{MV}$ photon beams produced from a Varian Clinac 21-EX (Varian Associates, Palo Alto, CA).

\subsection{Film measurements}

The films for this study included the Ready-Pack extended dose range Kodak EDR (Eastman Kodak Co., Rochester, NY) film and the Ready-Pack film Kodak XV. Sensitometric measurements were performed for three square field sizes $\left(3 \times 3 \mathrm{~cm}^{2}, 10 \times 10 \mathrm{~cm}^{2}\right.$ and $\left.25 \times 25 \mathrm{~cm}^{2}\right)$ and depths $\left(d_{\max }, 5 \mathrm{~cm}\right.$ and $\left.15 \mathrm{~cm}\right)$, with films exposed perpendicularly to the beam central axis. For the $3 \times 3 \mathrm{~cm}^{2}$ field size, each film was cut into four pieces (in order to minimize film wastage) and the envelopes were sealed with electrical tape. The films were sandwiched between slabs of solid water (Gammex RMI, Middleton, WI) having dimensions of $40 \times 40 \mathrm{~cm}^{2}$ and variable thicknesses. A combined thickness of $20 \mathrm{~cm}$ solid water was placed beneath the film at $15 \mathrm{~cm}$ depth to ensure adequate backscatter for these experiments. All films were irradiated in the 'perpendicular' geometry with the radiation beam incident at right angles to the surface of the solid water phantom at an SSD of $90 \mathrm{~cm}$. For Kodak EDR films, exposures were taken at each of the following monitor units (MU): $0,20,50,75,100,150,200,250,350$ and 500. Kodak XV films were irradiated at each of the following MU: 0, 1, 3, 5, 10, 20, 30, 50, 70, 80, 100, 120, 150 and 170. This corresponded roughly to a dose range of 0 to $550 \mathrm{cGy}$ for Kodak EDR film and 0 to $170 \mathrm{cGy}$ for Kodak XV film. The $0 \mathrm{MU}$ film corresponded to a film from each type that was developed without being irradiated, to determine base plus fog optical density levels.

In order to minimize potential experimental errors with film dosimetry, several precautions were taken. All irradiated films were taken from the same batch. All measurements were conducted on the same day (within a $14 \mathrm{~h}$ period). Each film was pin pricked to remove unwanted air in the envelope. In addition, solid water overlying films at the $d_{\text {max }}$ depth were manually compressed and taped at the edges to eliminate air pockets and offer even contact of the film with the phantom.

Fractional central axis depth dose and profile measurements using both film types were conducted on the same day as those for the film sensitometric characterization for field sizes of $3 \times 3 \mathrm{~cm}^{2}, 10 \times 10 \mathrm{~cm}^{2}$ and $25 \times 25 \mathrm{~cm}^{2}$, at both photon energies. Profile measurements were carried out in the 'perpendicular' geometry at depths of $d_{\max }, 5 \mathrm{~cm}$ and $10 \mathrm{~cm}$ within the solid water phantom. Depth doses were measured in the 'parallel' geometry with the gantry positioned at $270^{\circ}$, and the beam central axis parallel to the depth axis of the film. An additional $2^{\circ}$ tilt was incorporated, as recommended in a study by Suchowerska et al (2001), in order to avoid the penetration of unattenuated primary beam between the slabs and to minimize the effects of air pockets. This method has also been adopted by other investigators, such as Danciu et al (2001). Each film was cut along an edge and taped with electrical tape; the taped edge was then positioned flush against the front surface (with respect to the incident beam) of the solid water. Films were sandwiched between $40 \mathrm{~cm}$ of solid water, thereby providing significant compression and minimizing errors due to air gaps between the film and solid water. For each session of measurements (at a given field size and depth), Kodak EDR and XV films were irradiated to $175 \mathrm{MU}$ and $40 \mathrm{MU}$, respectively - these doses fall approximately within the centre of the linear region of the sensitometric curves for each film type. 


\subsection{Film processing and analysis}

All films were processed on the same day, the day after irradiation, using a Kodak X Omat3000 RA, automatic film processor with a 90 s processing time. Several test films were developed before the start of processing in order to stabilize the processing conditions. The developer temperature was stable at $37.2^{\circ} \mathrm{C}$ throughout the study. Stability of the processor was also verified by processing and checking the optical densities of unexposed films at regular intervals during the development process. Net optical densities (OD) were plotted against dose to generate sensitometric curves; the net OD is defined as the OD read by the densitometer minus the OD due to background base plus fog. Dose for a given energy, field size and depth was determined from the dosimetric beam parameters and the calibration factor relating the output of the linac. The calibration factor $(0.8 \mathrm{cGy} / \mathrm{MU})$ is determined at calibration conditions: $90 \mathrm{~cm} \mathrm{SSD,} 10 \times 10 \mathrm{~cm}^{2}$ at a depth of $10 \mathrm{~cm}$ in water.

Films irradiated for fractional depth dose and profile analysis were scanned and transformed to digitized images using a Lumiscan 75 laser film scanner (Lumisys, Sunnyvale, CA) with a $0.025 \mathrm{~cm} /$ pixel, 12 bit resolution. These images were subsequently analysed with the UMPlan treatment planning system (University of Michigan in-house planning system), which contains several analysis tools for film post-processing. The conversion from optical density to dose for all depth dose and profile measurements was accomplished using sensitometric curves at the given field size and a depth of $5 \mathrm{~cm}$; no depth dependence of the sensitometric curves were included for this conversion. Fractional depth dose curves for a given field size were normalized at a depth of $5 \mathrm{~cm}$.

\subsection{Ionization measurements}

Fractional depth doses and beam profiles were measured using a Wellhöfer type CC-13 cylindrical ion chamber (with a $3 \mathrm{~mm}$ inner radius and a $0.13 \mathrm{~cm}^{3}$ active volume) within a Scanditronix-Wellhöfer water phantom system (Scanditronix-Wellhöfer, Uppsala, Sweden). Field sizes for these measurements included $3 \times 3 \mathrm{~cm}^{2}, 10 \times 10 \mathrm{~cm}^{2}$ and $25 \times 25 \mathrm{~cm}^{2}$, with profiles measured for each field at depths of $d_{\max }, 5 \mathrm{~cm}$ and $10 \mathrm{~cm}$. All measurements were carried out with a $90 \mathrm{~cm}$ SSD for both $6 \mathrm{MV}$ and $15 \mathrm{MV}$ photon beams. A comparison between measurements in water versus those in solid water was carried out to determine the influence of the difference in composition between these two materials on the fractional depth dose. These measurements were performed using the CC-13 cylindrical ion chamber positioned within a specially designed cavity in a solid water slab. Solid water slabs of varying thickness, up to a total thickness of $13 \mathrm{~cm}$, were placed above the chamber to provide the depth variation for the depth dose measurement. Identical geometries were used for the comparison of fractional depth dose measurements in water and solid water: $90 \mathrm{~cm} \mathrm{SSD,} 10 \times 10 \mathrm{~cm}^{2}$ and $20 \times$ $20 \mathrm{~cm}^{2}$ field sizes, $6 \mathrm{MV}$ photons.

\section{Results and discussion}

\subsection{Uncertainty estimates}

For those films irradiated for sensitometric analysis, optical densities were read out using a Digital Densitometer II (Sun Nuclear Corporation, Melbourne, FL) optical densitometer. The uncertainty associated with the optical density reader with respect to linearity and stability was estimated to be within $\pm 1 \%$. In order to determine the optical density variation from a set of films, the optical densities of eight films from a given depth and field size, each 


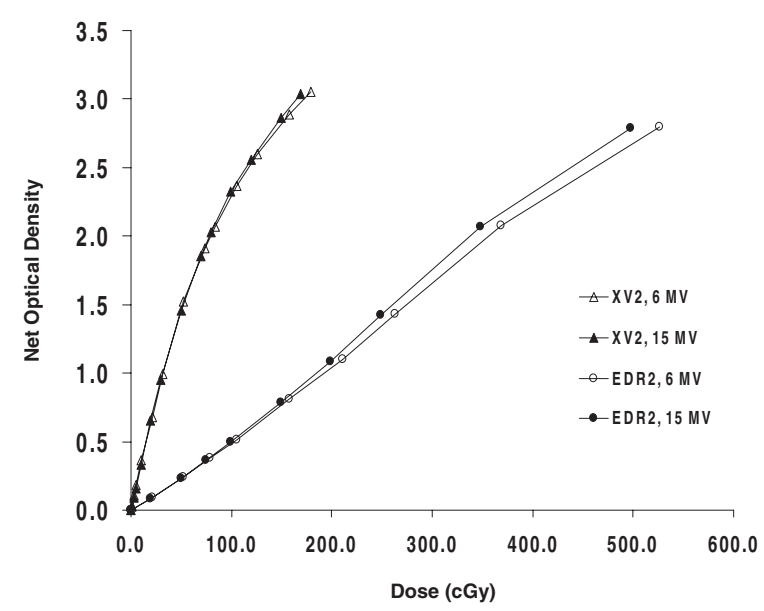

Figure 1. Sensitometric curves for Kodak EDR and XV films for $6 \mathrm{MV}$ and $15 \mathrm{MV}$ photons, for a $10 \times 10 \mathrm{~cm}^{2}$ field size at a $5 \mathrm{~cm}$ depth in the phantom.

Table 1. Optical density ratios, $15 \mathrm{MV}$ versus $6 \mathrm{MV}$, for field sizes of $3 \times 3 \mathrm{~cm}^{2}, 10 \times 10 \mathrm{~cm}^{2}$ and $25 \times 25 \mathrm{~cm}^{2}$ at dose levels of 50,150 and $350 \mathrm{cGy}$ for EDR and XV films.

\begin{tabular}{rlllllll}
\hline & \multicolumn{2}{c}{ XV film $[\mathrm{OD}(15 \mathrm{MV}) / \mathrm{OD}(6 \mathrm{MV})]$} & & \multicolumn{2}{c}{ EDR film $[\mathrm{OD}(15 \mathrm{MV}) / \mathrm{OD}(6 \mathrm{MV})]$} \\
\cline { 2 - 4 } \cline { 6 - 7 } & $3 \times 3 \mathrm{~cm}^{2}$ & $10 \times 10 \mathrm{~cm}^{2}$ & $25 \times 25 \mathrm{~cm}^{2}$ & & $3 \times 3 \mathrm{~cm}^{2}$ & $10 \times 10 \mathrm{~cm}^{2}$ & $25 \times 25 \mathrm{~cm}^{2}$ \\
\hline $50 \mathrm{cGy}$ & 1.03 & 1.01 & 1.02 & 1.01 & 1.01 & 1.02 \\
$150 \mathrm{cGy}$ & 1.01 & 1.02 & 1.01 & 1.03 & 1.03 & 1.04 \\
$350 \mathrm{cGy}$ & - & - & - & 1.03 & 1.04 & 1.05 \\
\hline
\end{tabular}

irradiated and processed identically, were read out and compared. This variation was found to be approximately $2 \%(1 \sigma)$ for both Kodak EDR and XV films. The calibration factor of the linear accelerator was verified using a calibrated ion chamber prior to film measurements, and was found to be within $0.3 \%$ of the used value $(0.8 \mathrm{cGy} / \mathrm{MU})$. We estimate that the calculation of dose from the given $\mathrm{MU}$ is within $\pm 0.5 \%$ for all field size and depth combinations.

\subsection{Sensitometric curves}

Figure 1 illustrates the variation in optical density as a function of dose for Kodak EDR and $\mathrm{XV}$ films. Included in this plot are the data for $6 \mathrm{MV}$ and $15 \mathrm{MV}$ photons for a $10 \times 10 \mathrm{~cm}^{2}$ field size at a fixed depth of $5 \mathrm{~cm}$ within the solid water phantom. The sensitometric response of Kodak EDR film is seen to increase linearly with dose until approximately 350 cGy, beyond which the curves appear to deviate from linearity. Above $350 \mathrm{cGy}$, the gradient of the sensitometric curves decreases. Kodak EDR film response is quite different from that of Kodak XV films. Kodak XV sensitometric curves are concave downward in shape and saturate at a much lower dose, 100-150 cGy, in comparison to Kodak EDR film. It is also noted in figure 1 that Kodak EDR film shows an increased sensitivity with increase in energy at higher doses. This result is corroborated in table 1 where the optical density ratios, $\mathrm{OD}(15 \mathrm{MV}) / \mathrm{OD}(6 \mathrm{MV})$, are presented for the $3 \times 3 \mathrm{~cm}^{2}, 10 \times 10 \mathrm{~cm}^{2}$ and $25 \times 25 \mathrm{~cm}^{2}$ field sizes, at dose levels of $50 \mathrm{cGy}$ and $150 \mathrm{cGy}$ for Kodak XV film and at $50 \mathrm{cGy}$, $150 \mathrm{cGy}$ and $350 \mathrm{cGy}$ for Kodak EDR film. At a dose level of $50 \mathrm{cGy}$, the response of 


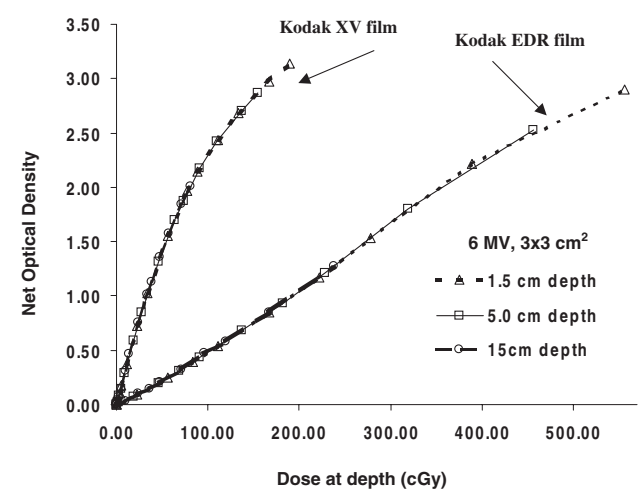

(a)

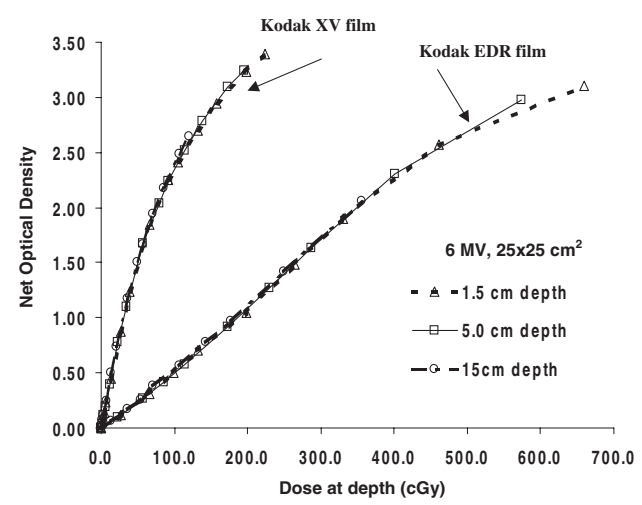

(c)

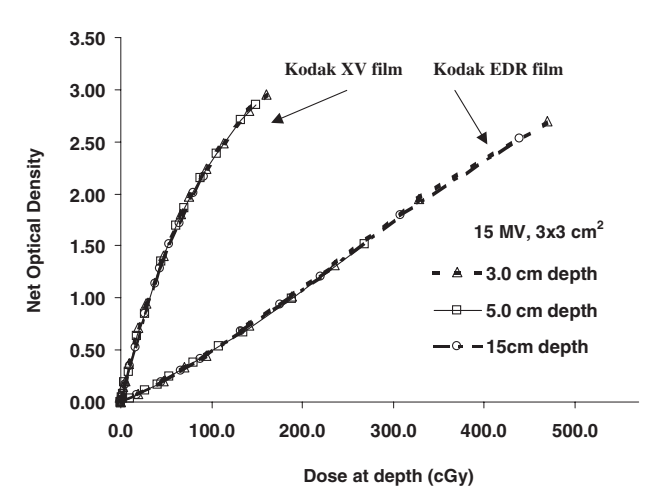

(b)

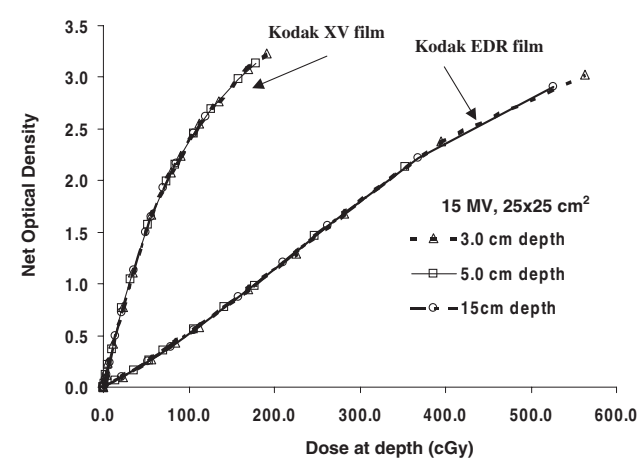

(d)

Figure 2. Sensitometric curves for Kodak EDR and XV films at depths of $d_{\max }(1.5 \mathrm{~cm}$ for $6 \mathrm{MV}, 3.0 \mathrm{~cm}$ for $15 \mathrm{MV}$ ), $5 \mathrm{~cm}$ and $15 \mathrm{~cm}$ in the phantom for (a) $6 \mathrm{MV}$ photons, $3 \times 3 \mathrm{~cm}^{2}$ field, (b) $15 \mathrm{MV}$ photons, $3 \times 3 \mathrm{~cm}^{2}$ field, (c) $6 \mathrm{MV}$ photons, $25 \times 25 \mathrm{~cm}^{2}$ field and (d) $15 \mathrm{MV}$ photons, $25 \times 25 \mathrm{~cm}^{2}$ field.

Kodak EDR film at $15 \mathrm{MV}$ is $1-2 \%$ higher than that at $6 \mathrm{MV}$ for the $3 \times 3 \mathrm{~cm}^{2}$ and $25 \times$ $25 \mathrm{~cm}^{2}$ field sizes. Kodak XV film optical density is seen to be higher by $1-3 \%$ at $15 \mathrm{MV}$ versus $6 \mathrm{MV}$ for the same three field sizes at a dose level of $50 \mathrm{cGy}$. As the dose level is increased, the ratio $\mathrm{OD}(15 \mathrm{MV}) / \mathrm{OD}(6 \mathrm{MV})$ increases by 3-5\% for Kodak EDR film. Furthermore, this ratio increases with field size, reaching a value of $5 \%$ for the $25 \times 25 \mathrm{~cm}^{2}$ field size at a dose of $350 \mathrm{cGy}$. The fact that $\mathrm{OD}(15 \mathrm{MV}) / \mathrm{OD}(6 \mathrm{MV})$ for Kodak XV film remains fairly constant at different dose levels and field sizes suggests that Kodak EDR film is more sensitive to changes in the beam energy and field size at larger doses. On the other hand, at lower doses ( $0-50 \mathrm{cGy})$ both Kodak EDR and XV film optical densities show similar behaviour with changes in the beam energy and field size. The data presented in figure 1 and table 1 for Kodak XV film are in good agreement with those of Danciu et al (2001), who have reported optical density variations within $2 \%$ for Kodak XV film irradiated at 6 MV and $18 \mathrm{MV}$, for a $15 \times 15 \mathrm{~cm}^{2}$ field size.

Figure 2 shows the sensitometric curves for Kodak EDR and XV films irradiated by $6 \mathrm{MV}$ and $15 \mathrm{MV}$ photons for $3 \times 3 \mathrm{~cm}^{2}$ and $25 \times 25 \mathrm{~cm}^{2}$ field sizes, at depths of $d_{\max }, 5 \mathrm{~cm}$ and $15 \mathrm{~cm}$ within the solid water phantom. The optical density differences observed in figure 2 (a) $\left(6 \mathrm{MV}, 3 \times 3 \mathrm{~cm}^{2}\right)$ are within $1 \%$ for both types of film. For example, at a dose 
level of $50 \mathrm{cGy}$, the largest variation in optical density with depth is $1.0 \%$ for Kodak XV film. The variation of optical density with depth is seen to be small (within 1\%) for Kodak XV film even at higher doses, above $150 \mathrm{cGy}$. For Kodak EDR film the largest optical density variation with depth is $1.0 \%$ and occurs at a dose level of $400 \mathrm{cGy}$. Differences in optical density seen in figure 2 (b) $\left(15 \mathrm{MV}, 3 \times 3 \mathrm{~cm}^{2}\right)$ are also small, and are found to be within $1 \%$ over all depths. The results presented in figures 2 (a) and (b) for the $3 \times 3 \mathrm{~cm}^{2}$ field size are in good agreement with those reported by Robar and Clark (1999), who showed maximum differences of $1.5 \%$ at a depth of $20 \mathrm{~cm}$ in the phantom for a $6 \mathrm{MV}$ beam, $2.5 \mathrm{~cm}$ diameter field. Figure 2(c) illustrates sensitometric curves for Kodak EDR and XV films irradiated by a $6 \mathrm{MV}, 25 \times 25 \mathrm{~cm}^{2}$ beam. Optical density differences with depth are on an average within $2 \%$ for both types of films, however, maximum differences of the order of 3-4\% are noted. At the $120 \mathrm{cGy}$ level, for example the variation in optical density for Kodak XV film between depths of $1.5 \mathrm{~cm}\left(d_{\max }\right)$ and $15 \mathrm{~cm}$ in the phantom is $2.6 \%$; the corresponding difference between these depths for Kodak EDR film is 2.5\%. This result for Kodak XV film is similar to that of Robar and Clark (1999) who showed an optical density difference of $3.0 \%$ between depths of $1 \mathrm{~cm}$ and $10 \mathrm{~cm}$ in a solid water phantom, for a $20 \times 20 \mathrm{~cm}^{2}, 6 \mathrm{MV}$ beam, at the $120 \mathrm{cGy}$ dose level. From figure 2(c), it is also evident that the variation in optical density with depth for Kodak EDR film increases at higher doses; the difference observed between $1.5 \mathrm{~cm}$ and $5 \mathrm{~cm}$ depths at the $570 \mathrm{cGy}$ dose level, for instance, is 3.5\%-this translates to a difference in dose of $5 \%$ for the same optical density about the 570 cGy dose level. Figure 2(d) illustrates sensitometric curves for Kodak EDR and XV films irradiated by a $15 \mathrm{MV}, 25 \times$ $25 \mathrm{~cm}^{2}$ beam. The differences in optical density with depth are, on an average, within $2 \%$ for both types of film. The variation in optical density with depth is generally smaller than that noted in figure 2 (c) $\left(6 \mathrm{MV}, 25 \times 25 \mathrm{~cm}^{2}\right.$ field), however is larger than that for the $15 \mathrm{MV}, 3 \times$ $3 \mathrm{~cm}^{2}$ field (figure 2(b)). The increase in optical density variation with depth from the $3 \times 3 \mathrm{~cm}^{2}$ to the $25 \times 25 \mathrm{~cm}^{2}$ fields can be explained if we consider that the $3 \times 3 \mathrm{~cm}^{2}$ field has a higher primary photon to scatter photon ratio than the $25 \times 25 \mathrm{~cm}^{2}$ field (Robar and Clark 1999). There is also a beam hardening effect with depth which prevails for the $3 \times 3 \mathrm{~cm}^{2}$ field; an opposite effect, beam softening, is observed for the $25 \times 25 \mathrm{~cm}^{2}$ field due to increased phantom scatter up to depths of $15 \mathrm{~cm}$ in the phantom. The result is that there are many more low energy photons, at greater depths for the $25 \times 25 \mathrm{~cm}^{2}$ field in comparison to the $3 \times 3 \mathrm{~cm}^{2}$ field, which accounts for the increased optical density response with depth at the larger field size. The smaller variation in optical densities noted for the $15 \mathrm{MV}, 25 \times 25 \mathrm{~cm}^{2}$ field (figure 2(d)) relative to that for the $6 \mathrm{MV}, 25 \times 25 \mathrm{~cm}^{2}$ field (figure 2(c)) is explained by the fact that the Compton scattering for a $15 \mathrm{MV}$ beam is more forward directed than that for a 6 MV beam.

Figure 3 illustrates the variation in optical density with depth for field sizes of $3 \times 3 \mathrm{~cm}^{2}$, $10 \times 10 \mathrm{~cm}^{2}$ and $25 \times 25 \mathrm{~cm}^{2}$, at a dose level of $50 \mathrm{cGy}$. Both Kodak EDR and XV film responses at energies of $6 \mathrm{MV}$ and $15 \mathrm{MV}$ are included in this figure. Each plot has been normalized to the optical density for a $10 \times 10 \mathrm{~cm}^{2}$ field at $5 \mathrm{~cm}$ depth. The optical density variation with field size and depth is quite similar for both types of film. The $3 \times 3 \mathrm{~cm}^{2}$ field size shows 1-2\% lower optical densities in all figures except for depths of $3 \mathrm{~cm}$ and $5 \mathrm{~cm}$ for Kodak XV film at $15 \mathrm{MV}$ (figure 3(d)), where the optical densities are $0.5 \%$ higher than the normalization value. In addition, the $3 \times 3 \mathrm{~cm}^{2}$ field exhibits the smallest variation in optical densities with depth (within 1-2\% for all figures) relative to the $10 \times 10 \mathrm{~cm}^{2}$ and $25 \times 25 \mathrm{~cm}^{2}$ fields. For the $25 \times 25 \mathrm{~cm}^{2}$ field, optical densities for Kodak EDR and XV films at both energies are consistently $2-4 \%$ higher than the normalization value; the $25 \times 25 \mathrm{~cm}^{2}$ field also shows the largest optical density variation with depth (2-4\%) with the highest differences $(3.5-4.5 \%)$ typically occurring at a depth of $15 \mathrm{~cm}$. These results at the $50 \mathrm{cGy}$ dose level are 


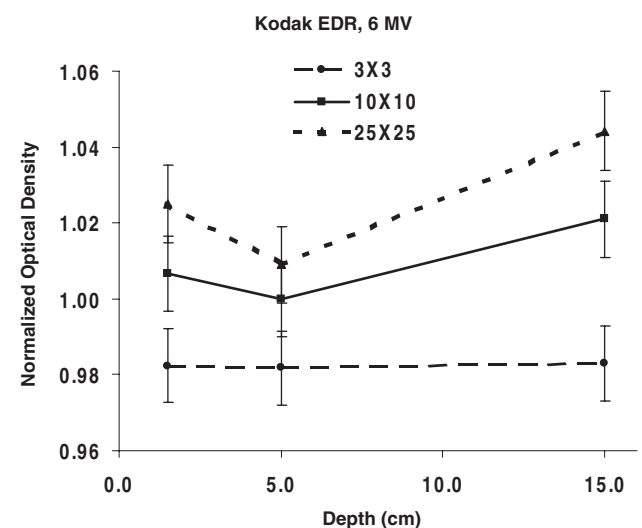

(a)

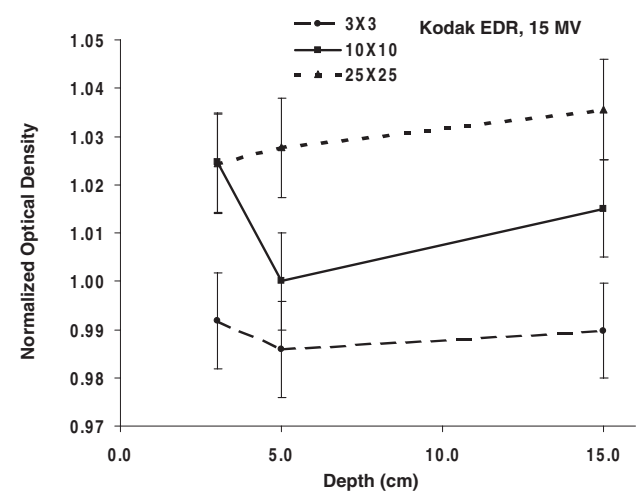

(c)

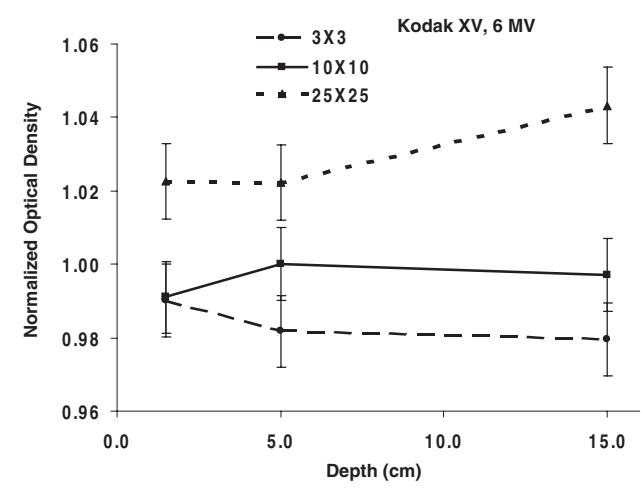

(b)

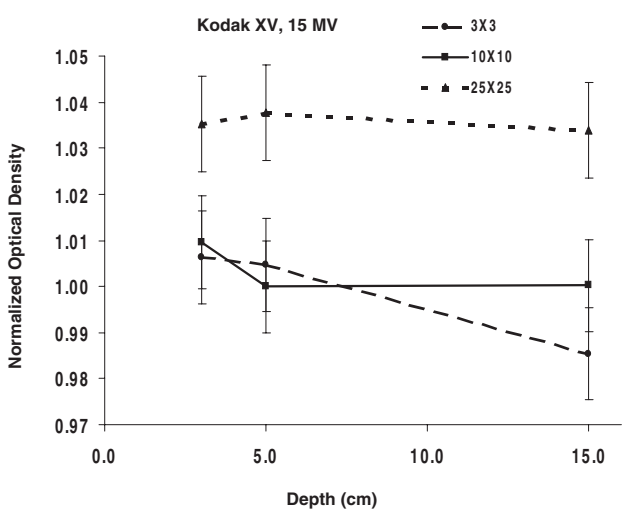

(d)

Figure 3. Normalized optical densities for a constant dose of $50 \mathrm{cGy}$ as a function of the field size and depth in the solid for (a) Kodak EDR film, 6 MV photons, (b) Kodak XV film, 6 MV photons, (c) Kodak EDR film, 15 MV photons and (d) Kodak XV film, 15 MV photons. The optical densities were normalized to the value for a $10 \times 10 \mathrm{~cm}^{2}$ field size at a depth of $5 \mathrm{~cm}$. The height of each error bar corresponds to one standard deviation $(1 \sigma)$ for the respective data point.

in agreement with the theory of increased primary photon to scatter photon ratios for the $3 \times$ $3 \mathrm{~cm}^{2}$ versus the $10 \times 10 \mathrm{~cm}^{2}$ and $25 \times 25 \mathrm{~cm}^{2}$ fields, and with the beam softening effects observed for the $25 \times 25 \mathrm{~cm}^{2}$ field at $15 \mathrm{~cm}$ depth as discussed previously. The data presented in figure 3 for Kodak XV film is in good agreement with the work of Sykes et al (1999), who found a $3.2 \%$ increase in optical density at $15 \mathrm{~cm}$ depth relative to $5 \mathrm{~cm}$ depth for a $25 \times$ $25 \mathrm{~cm}^{2}, 4 \mathrm{MV}$ field, at a dose level of $30 \mathrm{cGy}$. Our findings for Kodak XV film are also in excellent agreement with those of van Battum and Heijmen (1995), who show similar trends in optical density variation with depth and field size as that noted in figure 3. For example, van Battum and Heijmen (1995) show a 1-2\% reduction in optical density for a $4 \times 4 \mathrm{~cm}^{2}$ field relative to the normalization value $\left(10 \times 10 \mathrm{~cm}^{2}, 5 \mathrm{~cm}\right)$ at the $50 \mathrm{cGy}$ dose level, which is similar to the variation observed for the $3 \times 3 \mathrm{~cm}^{2}$ field in this work. van Battum and Heijmen (1995) also found increase in optical density in the order of $2-3 \%$ for a $20 \times 20 \mathrm{~cm}^{2}$ field size and $4 \%$ increase for a $30 \times 30 \mathrm{~cm}^{2}$ field; the same trend is noted in this report for the $25 \times$ $25 \mathrm{~cm}^{2}$ field size. 


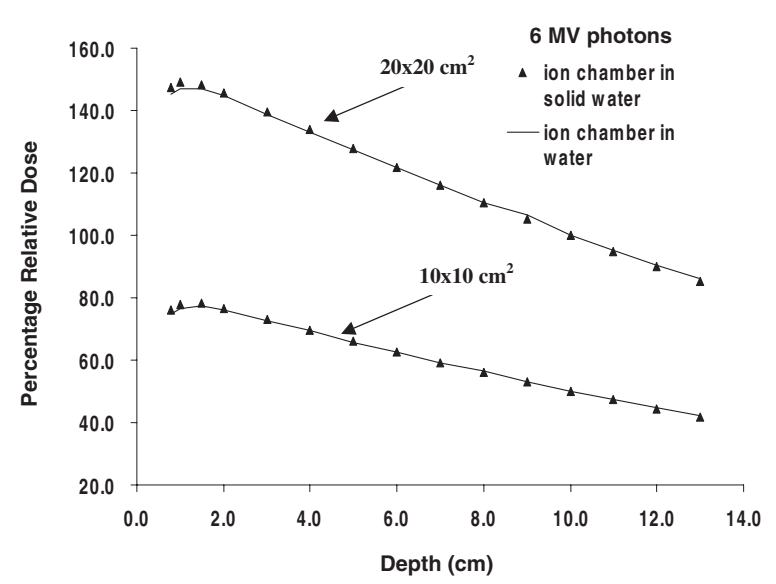

Figure 4. Percentage depth doses measured with the ion chamber in water and solid water for $6 \mathrm{MV}$ photons, $10 \times 10 \mathrm{~cm}^{2}, 20 \times 20 \mathrm{~cm}^{2}$ field sizes. Each curve has been normalized to the dose at a depth of $10 \mathrm{~cm}$. The $10 \times 10 \mathrm{~cm}^{2}$ field size plot includes a scaling factor of 0.5 for illustration purposes.

\subsection{Depth dose and profile comparisons}

Figure 4 shows the percentage depth dose curves measured in water and solid water with an ion chamber, for the $6 \mathrm{MV}$ photon beam for $10 \times 10 \mathrm{~cm}^{2}$ and $20 \times 20 \mathrm{~cm}^{2}$ field sizes. Both curves have been normalized at $10 \mathrm{~cm}$ depth; the $20 \times 20 \mathrm{~cm}^{2}$ field size data has been additionally scaled by a factor of 0.5 for ease of illustration. Relative dose differences between solid water and water are, on an average, within $0.5 \%$, confirming that the comparison between film measurements in water and ion chamber measurements in solid water is unbiased by minor differences in the electron densities between these two materials.

Figure 5 illustrates the fractional depth dose curves measured with Kodak EDR, XV films, and the ion chamber for $6 \mathrm{MV}$ (figure 5(a)) and $15 \mathrm{MV}$ (figure 5(b)) photon beams. Curves are shown for three field sizes: $3 \times 3 \mathrm{~cm}^{2}, 10 \times 10 \mathrm{~cm}^{2}$ and $25 \times 25 \mathrm{~cm}^{2}$. All curves have been normalized at $5 \mathrm{~cm}$ depth; the data for the $3 \times 3 \mathrm{~cm}^{2}$ and $25 \times 25 \mathrm{~cm}^{2}$ fields have been scaled by factors of 0.5 and 1.5 , respectively, for ease of illustration. Film optical densities were converted to dose using sensitometric curves for the given field size at a depth of $5 \mathrm{~cm}$. Kodak EDR film shows good agreement versus Kodak XV film and the ion chamber measurements for the $3 \times 3 \mathrm{~cm}^{2}$ and $10 \times 10 \mathrm{~cm}^{2}$ field sizes over the range of depths from $d_{\max }$ to $20 \mathrm{~cm} ; 2-3 \%$ differences noted between Kodak EDR, XV films and the ion chamber data in the $d_{\max }$ region and at depths greater than $15 \mathrm{~cm}$, are within the experimental uncertainty for these measurements. Larger differences are observed for the $25 \times 25 \mathrm{~cm}^{2}$ field size. In figure 5(a) (6 MV beam) at a depth of $1.5 \mathrm{~cm}\left(d_{\max }\right)$, for example, Kodak EDR and XV films are found to be $2.8 \%$ and $7.5 \%$ lower than the ion chamber data, respectively. At a depth of $17 \mathrm{~cm}$ in the phantom, Kodak EDR and XV films are, respectively, $2.9 \%$ and $4.9 \%$ higher relative to ion chamber measurements; the $2 \%$ difference here is considered to be within the experimental uncertainty. Similar trends are observed for the $15 \mathrm{MV}$ beam (figure 5(b)). The largest discrepancies between the film and ion chamber measurements are found for the $25 \times$ $25 \mathrm{~cm}^{2}$ field size. In the build-up region $(1.5 \mathrm{~cm}$ depth) differences between the film and ion chamber are $0.9 \%$ (Kodak EDR film) and 3.9\% (Kodak XV film); at a depth of $17 \mathrm{~cm}$ in the phantom the corresponding differences are $4.6 \%$ (Kodak EDR film) and $3.3 \%$ (Kodak $\mathrm{XV}$ film). For comparison purposes, the film optical densities for the $25 \times 25 \mathrm{~cm}^{2}$ field size, 


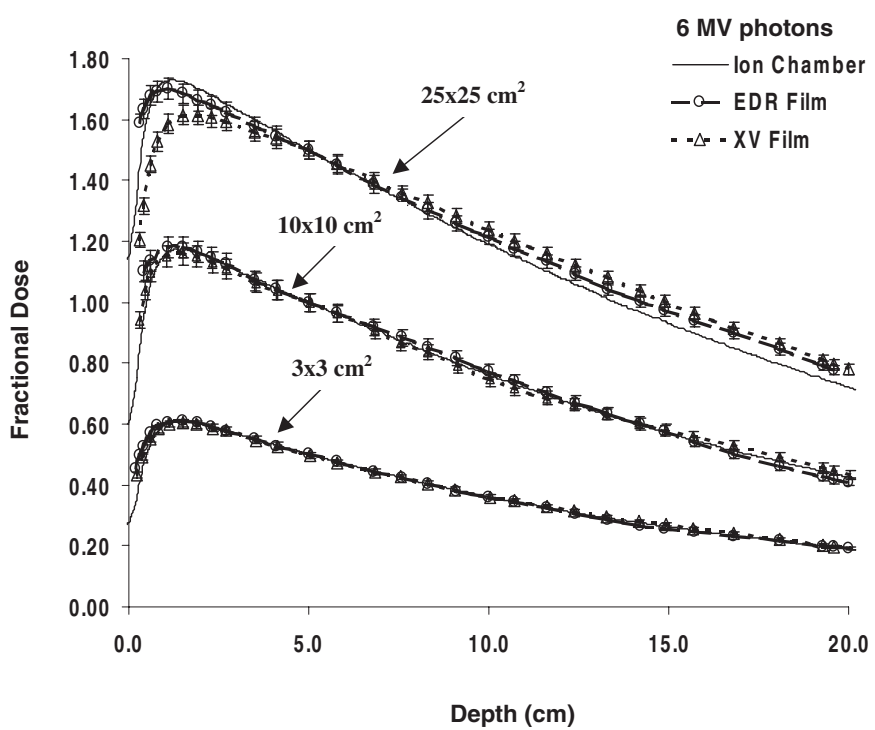

(a)

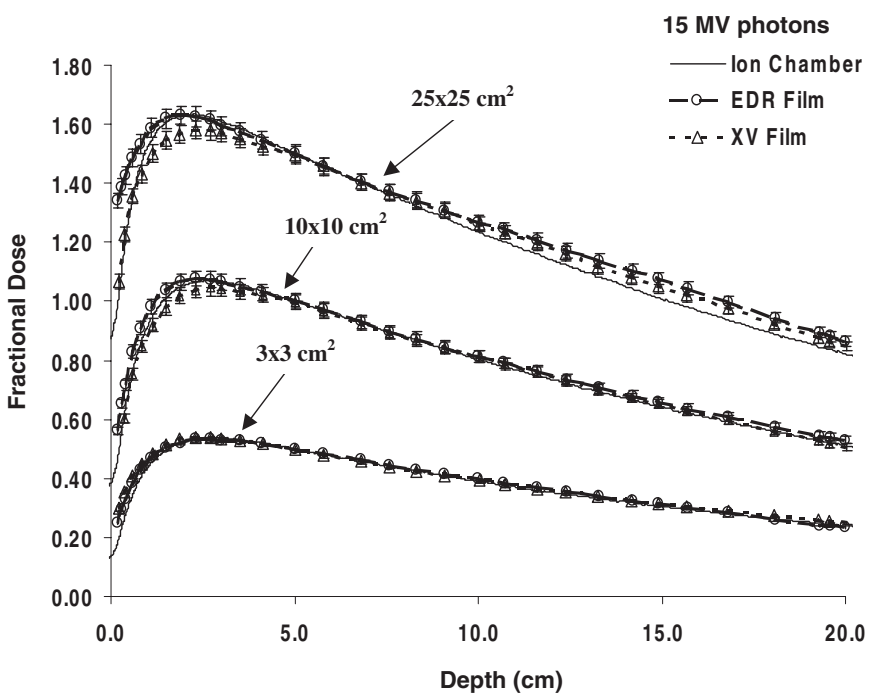

(b)

Figure 5. Fractional depth doses measured with Kodak EDR and XV films and the ion chamber in solid water for $3 \times 3 \mathrm{~cm}^{2}, 10 \times 10 \mathrm{~cm}^{2}$ and $25 \times 25 \mathrm{~cm}^{2}$ field sizes, for (a) $6 \mathrm{MV}$ photons and (b) $15 \mathrm{MV}$ photons. Each curve has been normalized to the dose at a depth of $5 \mathrm{~cm}$. The data for the $3 \times 3 \mathrm{~cm}^{2}$ and $25 \times 25 \mathrm{~cm}^{2}$ fields have been additionally scaled by factors of 0.5 and 1.5 , respectively, for ease of illustration. The error bars correspond to an estimated experimental uncertainty of $\pm 2 \%$ for the respective data point.

for depths from $10 \mathrm{~cm}$ to $20 \mathrm{~cm}$, were converted to dose using the sensitometric curve at a depth of $15 \mathrm{~cm}$. This was found to produce a small improvement in the film doses at depth. The agreement between film (both Kodak EDR and XV films) and ion chamber, at a depth 


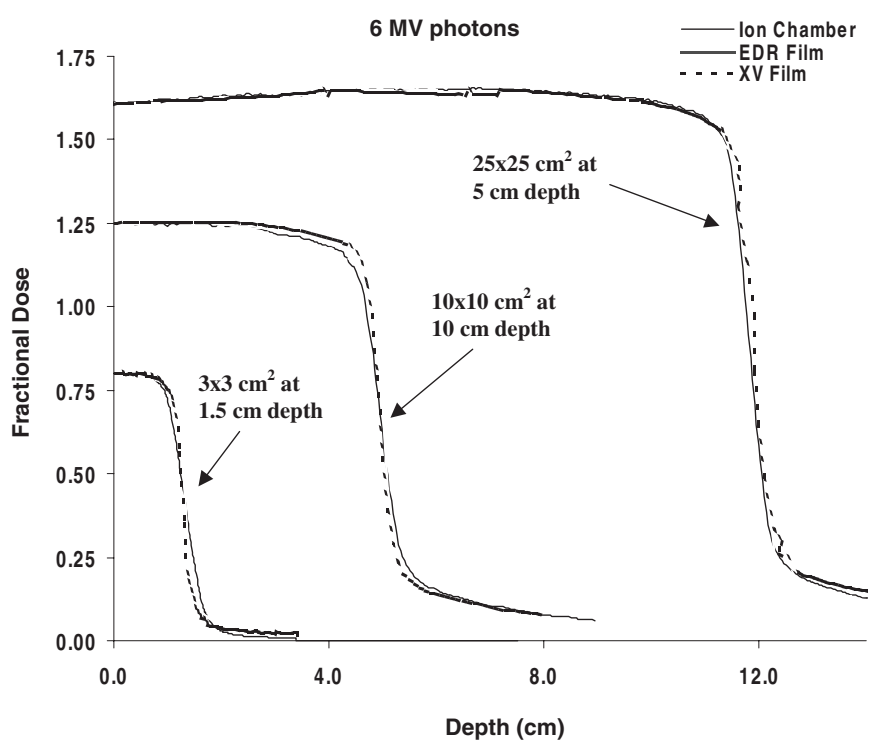

(a)

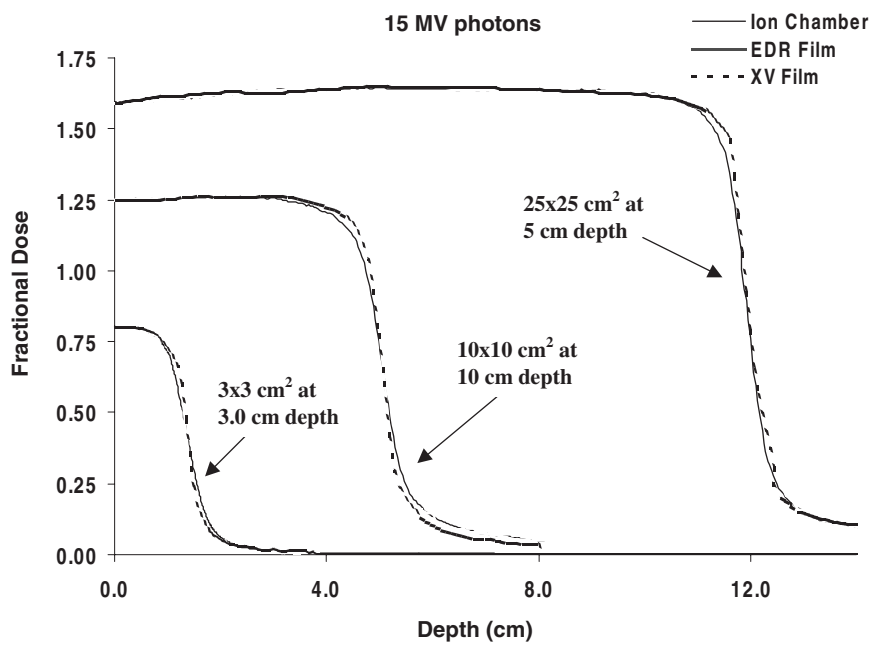

(b)

Figure 6. Fractional profile doses measured with Kodak EDR film and Kodak XV film and the ion chamber in solid water for $3 \times 3 \mathrm{~cm}^{2}(1.5 \mathrm{~cm}$ depth $), 10 \times 10 \mathrm{~cm}^{2}(10 \mathrm{~cm}$ depth) and $25 \times$ $25 \mathrm{~cm}^{2}$ ( $5 \mathrm{~cm}$ depth) field sizes, for (a) $6 \mathrm{MV}$ photons and (b) $15 \mathrm{MV}$ photons. Each curve has been normalized to the respective central axis value. Scaling factors of $0.8,1.25$ and 1.6 are included for the $3 \times 3 \mathrm{~cm}^{2}, 10 \times 10 \mathrm{~cm}^{2}$ and $25 \times 25 \mathrm{~cm}^{2}$ fields, respectively, for illustration purposes.

of $17 \mathrm{~cm}$, was improved by $0.5 \%$ for the $6 \mathrm{MV}$ depth dose curve and by $1.0 \%$ for the $15 \mathrm{MV}$ curve using the sensitometric curve at $15 \mathrm{~cm}$ depth versus that at $5 \mathrm{~cm}$ depth for the dose conversion. The results shown in figure 5 indicate that the response with the field size and depth is similar to that of Kodak XV film; the increase in scatter with depth for the $25 \times 25 \mathrm{~cm}^{2}$ field size causes both Kodak EDR and XV films to over-respond by 3-5\% with depth relative 
to ion chamber measurements. The findings noted in the fractional doses at the largest field size for Kodak XV film (figure 5) are consistent with those of Cadman (1998) who reported an under-response of 5\% in the build-up region and an over-response of $6 \%$ (at $17 \mathrm{~cm}$ depth in phantom) relative to ion chamber measurements for a $4 \mathrm{MV}$ beam.

Figure 6 illustrates the relative profile doses for $6 \mathrm{MV}$ (figure 6(a)) and $15 \mathrm{MV}$ (figure 6(b)) photon beams. Included in these plots are the profiles for various field sizes at different depths: $3 \times 3 \mathrm{~cm}^{2}$ at $d_{\max }, 10 \times 10 \mathrm{~cm}^{2}$ at $10 \mathrm{~cm}$ and $25 \times 25 \mathrm{~cm}^{2}$ at $5 \mathrm{~cm}$. Curves have been normalized to their respective central axis values. Scaling factors of $0.8,1.25$ and 1.6 are included for the $3 \times 3 \mathrm{~cm}^{2}, 10 \times 10 \mathrm{~cm}^{2}$ and $25 \times 25 \mathrm{~cm}^{2}$ fields, respectively, for illustration purposes. Kodak EDR film is in good agreement with Kodak XV film and the ion chamber measurements for all field sizes for both $6 \mathrm{MV}$ and $15 \mathrm{MV}$ photons. Average differences between film (both types of film) and ion chamber measurements are within $2 \%$ in the inner profile region (dose $>90 \%$ ), as well as in the outer profile region (dose $<20 \%$ ); the penumbral region is within $2 \mathrm{~mm}$ distance-to-agreement among all field sizes. It is clearly observed in the data presented in figure 6 that the profiles measured with the film have a steeper fall-off in the penumbral region compared with that of the ion chamber. This is due to the higher spatial resolution of the film and the volume averaging effect of the ion chamber; the 'rounding' of the profile shoulders due to this effect is most emphasized with the smallest field size $\left(3 \times 3 \mathrm{~cm}^{2}\right)$. The effect of the blurring due to different detector line spread functions has been reported by Charland et al (1998) and García-Vicente et al (1998), who have found that the penumbras observed with film are smaller than those obtained with ion chambers. The good overall agreement between the film and ion chamber measurements (in figure 6) suggests that film is not significantly influenced by the off-axis variation in the energy spectrum that results from increased scattering in the profile penumbral and tail regions, a finding that is consistent with the work of van Battum and Heijmen (1995). The profiles in figure 6 also serve to illustrate that the response of Kodak EDR film is nearly the same as that of Kodak $\mathrm{XV}$ film for relative profile dosimetry over a variety of field sizes and depths.

\section{Conclusions}

The optical density as a function of dose is found to be linear in the range from 0 to 350 cGy for a new type of film, Kodak EDR. The sensitometric response of Kodak EDR film as a function of the field size and depth in the phantom is observed to be similar to that of another extensively tested film, Kodak XV, when irradiated by $6 \mathrm{MV}$ and $15 \mathrm{MV}$ photon beams. Additionally, Kodak EDR film is shown to be accurate within $2 \% / 2 \mathrm{~mm}$ for fractional, central axis depth doses and profiles over a range of field sizes and depths in the phantom. Kodak EDR film over-responds relative to the ion chamber in the order of $3-5 \%$ for the largest field size $(25 \times$ $25 \mathrm{~cm}^{2}$ ) at depths greater than $15 \mathrm{~cm}$, a result which is consistent with that of Kodak XV film. This level of agreement versus the ion chamber measurements found in this study suggests that Kodak EDR film may be used for accurate $( \pm 5 \%)$ relative dosimetry over a range of clinically encountered beam energies and field sizes. This work also shows that Kodak EDR film can be used for quality assurance at higher dose ranges, such as those encountered in dose escalation in the context of IMRT. Kodak EDR film offers a significant advantage over Kodak XV film for quality assurance at higher dose ranges.

\section{Acknowledgments}

This work has been supported in part by NIH Grant P01-CA59827. The authors would like to thank Shigeru Yokoyama for providing the measurements for the depth dose comparisons 
between water and solid water. The authors also acknowledge the assistance of Jean Moran with the UMPlan film analysis software.

\section{References}

Burch S E, Kearfott K J, Trueblood J H, Sheils W, Yeo J and Wang C K 1997 A new approach to film dosimetry for high energy photon beams: lateral scatter filtering Med. Phys. 24 775-83

Cadman P 1998 Use of CEA TVS film for measuring high energy photon beam distributions Med. Phys. 25 1435-37

Charland P, El-Khatib E and Wolters J 1998 The use of deconvolution and total least squares in recovering a radiation detector line spread function Med. Phys. 25 152-60

Cheng C-W and Das I J 1996 Dosimetry of high energy photon and electron beams with CEA films Med. Phys. 23 1225-32

Danciu C, Proimos B S, Rosenwald J and Mijnheer B J 2001 Variation of sensitometric curves of radiographic films in high energy photon beams Med. Phys. 28 966-74

Evans M D C and Schreiner L J 1992 A simple technique for film dosimetry Radiother. Oncol. 23 265-7

García-Vicente F, Delgado J M and Peraza C 1998 Experimental determination of the convolution kernel for the study of the spatial response of a detector Med. Phys. 25 202-7

Hale J I, Kerr A T and Shragge P C 1994 Calibration of film for accurate megavoltage photon dosimetry Med. Dosim. $1943-6$

Mayer R, Williams A, Frankel T, Chong Y, Simons S, Yang N and Timmerman R 1997 Two-dimensional film dosimetry application in heterogeneous materials exposed to megavoltage photon beams Med. Phys. 24 455-60

McLaughlin W L, Chen Y, Soares C G, Miller A, Van Dyke G V and Lewis D F 1995 Sensitometry of the response of a new radiochromic film dosimeter to gamma radiation and electron beams Nucl. Instrum. Methods Phys. Res. 302 165-7

Muench P J, Meigooni A S, Nath R and McLaughlin W L 1991 Photon energy dependence of the sensitivity of radiochromic film and comparison with silver halide film and LiF TLDs used for brachytherapy dosimetry Med. Phys. 18 769-75

Robar J L and Clark B G 1999 The use of radiographic film for linear accelerator stereotactic radiosurgical dosimetry Med. Phys. 26 2144-50

Stern R L, Fraass B A, Gerhardsson A, McShan D L and Lam K L 1992 Generation and use of measurement-based 3-D dose distributions for 3-D dose calculation verification Med. Phys. 19 165-73

Suchowerska N, Hoban P, Butson M, Davidson A and Metcalfe P 2001 Directional dependence in film dosimetry: radiographic and radiochromic film Phys. Med. Biol. 46 1391-7

Suchowerska N, Hoban P, Davidson A and Metcalfe P 1999 Perturbation of radiotherapy beams by radiographic film: measurements and Monte Carlo simulations Phys. Med. Biol. 44 1755-65

Sykes J R, James H V and Williams P C 1999 How much does film sensitivity increase at depth for larger fields? Med. Phys. 26 329-30

van Battum L J and Heijmen B J M 1995 Film dosimetry in water in a 23 MV therapeutic photon beam Radiother. Oncol. 34 152-9

van Bree N A M, Izdes M H M, Huizenga H and Mijnheer B J 1994 Film dosimetry for radiotherapy treatment planning verification of a 6 MV tangential breast irradiation Radiother. Oncol. 31 251-5

Williamson J F, Khan F M and Sharma S C 1981 Film dosimetry of megavoltage photon beams: a practical method of intensity-to-isodose curve conversion Med. Phys. 8 94-8 